\title{
Comparative Pharmacokinetic Study and Quantification of Ibuprofen released from Interpenetrating polymer Network Beads of Sodium Carboxymethyl Xanthan and Sodium Alginate
}

\author{
Saumen Karan, Rajib Pal, Biswajit Ruhidas, Saswata Banerjee, Tapan Kumar Chatterjee \\ Department of Pharmaceutical Technology, Jadavpur University, Kolkata-32, INDIA.
}

\begin{abstract}
Aim: The purpose of this study was to determine the pharmacokinetic parameters of ibuprofen (IBP) in rabbits following administration of the drug-loaded interpenetrating network (IPN) beads and to compare the bioavailability of the drug from IPN beads with that from pure IBP and IBP Suspension. Materials and Methods: IPN beads, sodium carboxymethyl xanthan and sodium alginate was prepared by inotropic gelation process using $\mathrm{AlCl}_{3}$ as a cross linking agent. The plasma drug concentration was determined by High Performance Liquid Chromatographic method according to validation guidelines 2001. The chromatographic separation was carried out in WATERX BDS, $C_{18}$ column with UV detection at $223 \mathrm{~nm}$. Result: Though the maximum plasma concentration $\left(\mathrm{C}_{\max }\right.$ $(32.11 \pm 2.03)$ ) obtained from pure IBP (control) was higher than that of IBP suspension (reference $\left(C_{\max } 30.05 \pm 1.93\right)$ ) and the time required to reach $C_{\max }\left(T_{\max }\right)$ was less in the control (1.41 \pm 0.37$)$ than that of the reference product, the $C_{\max }$ was significantly less and $T_{\max }(2.91 \pm 0.5)$ was higher from the drug loaded IPN beads than those from the both control and reference. Conclusions: Moreover, the relative bioavailability of the drug from the IPN beads was higher from the both control and reference products. This study revealed that IPN beads could be a suitable dosage form for IBP to achieve a sustained drug release.
\end{abstract}

Key words: IPN, Pharmacokinetic, Relative bioavailability, HPLC, Ibuprofen.

\section{INTRODUCTION}

Pain related disorders are increasing worldwide and elderly people are mostly affected. To overcome this menace, different nonsteroidal anti-inflammatory drugs (NSAID) have been incorporated and Ibuprofen which is a first member of propionic acid derivative comes into picture. It exhibits poor solubility in water, poor compressibility and is unstable for tablet preparation by direct compression method due to its excessive elastic recovery. ${ }^{1}$ It has Pka 5.3, rapidly absorbed after oral administration (45 to $90 \mathrm{~min}$ ), is extensively bound to plasma proteins $(99 \%)$ and has a relatively short elimination half-life
(55 to $150 \mathrm{~min}$ ). ${ }^{2}$ Structure of Aceclofenac (IS) and Ibuprofen are shown in Figure 1.

A large number of natural polymers like sodium alginate (SAL), chitosan, xanthan gum, guar gum, locust bean gum are used as hydrophilic matrix forming material because of their bio-compatibility and capacity to absorb large quantities of water or biological fluid. ${ }^{3}$ Xanthan gum is an extracellular polysaccharide obtained from gram negative bacteria Xanthomonas campestris which is extensively used in pharmaceutical formulation as suspending, thickening, emulsifying component of matrix tablets and pellets. ${ }^{4}$
Submission Date : 10-06-2016 Revision Date : 12-07-2016 Accepted Date : :27-07-2016

DOI: 10.5530/ijper.50.3.18 Correspondence:

Dr. Tapan Kumar Chatterjee Department of Pharmaceutical Technology, Jadavpur University, Kolkata-32, INDIA.

Phone no: +919836066927 E-mail: crctkc@gmail.com

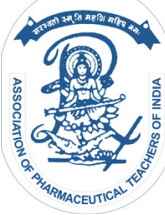

www.ijper.org 
However unlike sodium alginate it is not capable of forming gelled beads with divalent or trivalent cations through ionotropic gelation process. Since the formation of gelled beads depends on the cooperative binding between carboxylic acid groups of polysaccharides with cations, it is assumed that number of carboxylic group in native xanthan gum is less. Alginate has been widely used in many fields such as cell immobilization, tissue engineering, microencapsulation of nutraceuticals and drugs, as well as in food applications as thickening, stabilizing and gelling agents and as alginate-based edible films and coatings for food products. ${ }^{5}$ Modification and derivatization of these polymers help in modulating the release of the drug by controlling their swelling capacity. Beads prepared by cross linking a single polymer or blend of polymers give rise to sustained release formulation. ${ }^{6}$ Controlled release or sustained release formulations of ibuprofen with non-irritant bio-compatible polymers provides protection to the gastro intestinal tract (GIT), which is damaged due to the adverse effect of NSAIDs. IBP loaded interpenetrating polymer network (IPN) bead has been formulated to reduce the irritation of GIT and to release the drug over a prolong period. ${ }^{7}$ In vitro study of IPN beads, prepared from sodium carboxy methyl xanthan (SCMX), SAL and IBP in the weight ratio 1.5:1.5:1.5 respectively in the presence of $2 \% \mathrm{w} / \mathrm{v} \mathrm{AlCl}_{3}$ as cross linking agent and gelled for half an hour, has shown to improve release by $13-14 \%$ in two hours in gastric fluid. In simulated intestinal fluid however 98\%-99.5\% drug was released in 4-5 hours. ${ }^{8}$

Different methods have already been published for quantification of ibuprofen in rabbit plasma, and depending upon analytical method modernization, we developed a HPLC method for ibuprofen quantification in rabbit plasma which is simple, reliable, cost effective, reproducible and above all having high level of accuracy and precision. Earlier we have developed various formulations of ibuprofen as a model drug and had evaluated their in-vitro parameters. ${ }^{6}$ A corresponding pharmacokinetics study has been conducted by our developed method. Here we have also studied in-vitro in-vivo correlation (IVIVC) and high correlation coefficient value which shows a good correlation exists between in-vitro and in-vivo data.

\section{MATERIALS AND METHODS}

Ibuprofen (IBP), aceclofenac (Internal standard (IS) and xanthan gum were obtained as gift samples from M/S Albert David Limited, Kolkata, India. Sodium alginate, $\mathrm{AlCl}_{3} \cdot 6 \mathrm{H}_{2} \mathrm{O}$, monochloroacetic acid, acetonitrile (HPLCGrade), water (HPLC-Grade) and Sodium dihydrogen phosphate were purchased from Merck specialities Private Ltd., Mumbai, India. The tube containing EDTA-2K (Merck Pvt. Ltd., Mumbai, India) was used as anticoagulant for plasma sample of rabbits. All the other reagents used were of analytical reagent grade. Ibugesic suspensions (B.NoDT0741, MFD.SEP.12, EXP.AUG.15, Mfd., each $5 \mathrm{ml}$ containing $100 \mathrm{mg}$ ibuprofen) were purchased from commercial source.

\section{Preparation of Ibuprofen Loaded IPN Beads}

IBP (1.5\%), accurately weighed, was uniformly dispersed in an aqueous solution containing required proportions of sodium carboxymethyl xanthan gum and sodium alginate (1.5:1.5). The IPN beads were prepared by extruding the polymeric dispersion $(10 \mathrm{ml})$ containing ibuprofen $(15 \mathrm{mg})$, into $2 \% \mathrm{w} / \mathrm{v}$ solution of aluminum chloride at a rate of $2 \mathrm{ml} / \mathrm{min}$, using $21 \mathrm{G}$ flat-tip hypodermic needle. The beads were collected by filtration, washed and dried to a constant weight at $45^{\circ} \mathrm{C}$ in hot air oven and then kept in desiccators.

\section{Treatment protocol}

\section{Animals}

The in vivo study was performed following the guidelines of 'Committee of Purpose of Control and Supervision of experiments on Animals (CPCSEA)', Ministry of Social Justice and Empowerment, Government of India and approved protocol by the Institutional Ethics Committee, Jadavpur University(CPCSEA, Reg. no. 367, Kolkata, India). Male New Zealand white rabbits weighing 1.5-2.0 kg were grouped and housed in wire cages and maintained under standard laboratory conditions (temperature $25 \pm 2^{\circ} \mathrm{C}$ ) with $14 \mathrm{~h}$ dark: $10 \mathrm{~h}$ light cycle. Rabbits were acclimatized for one week and they were allowed free access to standard dry pellet diet and water ad libitum.

\section{Estimation of Ibuprofen from rabbit plasma}

Maximum therapeutic oral dose of IBP in adult human is $1200 \mathrm{mg} /$ day. Based on Body Surface Area, the oral therapeutic dose in rabbit was nearly $60 \mathrm{mg} / \mathrm{kg}$. Dose conversation was done according to proposed formula by Food and Drug Administration, 2002. 'The study was designed to compare the pharmacokinetic profiles of IBP between the control, reference and IBP loaded IPN beads in healthy rabbits. The pure IBP and the IPN beads loaded with ibuprofen were suspended in 1\% carboxy methyl cellulose (CMC) solution. The studies were demonstrated on fasting rabbits that were deprived of food but not water for $12 \mathrm{hrs}$ prior to experiment, following oral administration of $60 \mathrm{mg} / \mathrm{kg}$ pure ibuprofen (control), $3 \mathrm{ml} / \mathrm{kg}$ Ibujesic suspension (reference) and 
$180 \mathrm{mg} / \mathrm{kg}$ IPN beads loaded with ibuprofen (test) in three different groups (each group contained six rabbits). Blood samples $(0.5 \mathrm{ml})$ were collected from marginal ear vain of rabbits by small 27 -gauge needle at a predetermined time interval of pre-dose, 0.5, 1.0, 1.5, 2.5, 3.0, 3.5, 4.0, 6.0, 12.0 and 24.0 hrs into the tubes containing EDTA-2K as an anticoagulant. Plasma was separated immediately by centrifuging the blood at $3500 \mathrm{rpm}$ for 15 min under refrigeration. Immediately after centrifugation the plasma was homogenized and stored at $-20^{\circ} \mathrm{C}$ until analyzed. ${ }^{10}$

\section{Instrument and Chromatographic conditions}

The concentrations of IBP in rabbit plasma were measured by High Performance Liquid Chromatography (ModelAMI2010; Analytical Technology Ltd.) system consisting of ANALCHROM Chromatography Workstation V.2.22 for the analysis and CLARITY software for the chromatogram analysis. The purity determination was performed on a stainless steel column (WATERX, SN 6820, 250×4 $\mathrm{mm}$, Esquire ODS2 $5 \mu \mathrm{m}$ ) with Octadecyl silane (ODS) chemically bonded to porous silica particles of $5 \mu \mathrm{m}$ diameter with ASPD detector and ALC pump (Analytical Technology Ltd., Gujarat, India). The mobile phase consisted of acetonitrile and phosphate buffer in the ratio of $50: 50(\mathrm{v} / \mathrm{v}, \mathrm{pH} 4.16)$ at ambient temperature and the flow rate was kept at $1.0 \mathrm{ml} / \mathrm{min}$. The sample of $20 \mu \mathrm{l}$ was injected through rheodyne injector system fitted with fixed $20 \mu \mathrm{l}$ fixed loop. The elution was monitored using UV detection at $223 \mathrm{~nm}$.

\section{Preparation of stock and standard solution}

The stock solutions of $1.0 \mathrm{mg} / \mathrm{ml}$ of the analyte (IBP) and $0.5 \mathrm{mg} / \mathrm{ml}$ of aceclofenac used as Internal Standard (IS), were prepared in acetonitrile. Working solution of different concentrations was prepared from above mention stock solution by diluting with mobile phase afresh before use.

\section{Preparation of calibration standards and quality control (QC) sample}

Seven point calibration curve was prepared by spiking appropriate amounts of working solution into the blank plasma to obtain final concentration of $5,10,20,40,60$, $80,100 \mu \mathrm{g} / \mathrm{ml}$ for the analysis. The Quality control (QC) samples were prepared to obtain the final concentration of $15 \mu \mathrm{g} / \mathrm{ml}$ (low QC), $45 \mu \mathrm{g} / \mathrm{ml}$ (mid QC) and $90 \mu \mathrm{g} / \mathrm{ml}$ (high QC) $\mu \mathrm{g} / \mathrm{ml}$. A working IS solution of $25 \mu \mathrm{g} / \mathrm{ml}$ was prepared in mobile phase. All stock solutions and working standard solutions were stored in polypropylene vials in a $-20^{\circ} \mathrm{C}$ freezer.

\section{Sample preparation}

For the calibration standards, in a $2-\mathrm{ml}$ micro centrifuge tube (Ependroff, USA), $250 \mu \mathrm{L}$ of plasma sample, $50 \mu \mathrm{L}$ of IS (equivalent $25 \mu \mathrm{g} / \mathrm{ml}$ ) and $300 \mu \mathrm{L}$ of acetonitrile were added and mixed for a minute, and then made up to $1 \mathrm{ml}$ with acetonitrile. The resulting solution was vortexed for $5 \mathrm{~min}$ and allowed to stand for $30 \mathrm{~min}$. Then centrifuged at 10,000 rpm for $10 \mathrm{~min}$ (Cooling Microfuge, Remi Instruments, Mumbai, India). The supernatant layer was separated and filtered through $0.22 \mu \mathrm{m}$ filter and $20 \mu \mathrm{l}$ injected into the HPLC system. ${ }^{11}$

\section{Validation of proposed method}

Above method was validated on the basis of US FDA bio-analytical method validation guidelines 2001. It was validated for specificity, linearity, accuracy, precision, sensitivity, recovery and stability.

\section{Specificity (Selectivity)}

In the conference report II, selectivity was defined as follows: Selectivity is the ability of bio-analytical method to measure unequivocally and to differentiate the analyte(s) in the presence of components, which may be expected to be present. ${ }^{12}$ The specificity of the method was done by using blank plasma of 6 different sources to test for interference at the retention time of ibuprofen and aceclofenac (IS).

\section{Linearity}

Seven different concentrations of ibuprofen with constant IS concentration were spiked to the blank plasma as describe previously. The linearity of calibration curve was obtained into the range of $5-100 \mu \mathrm{g} / \mathrm{ml}$ in plasma sample and it was obtained from least squares linear regression presented with their correlation coefficients.

\section{Accuracy and precision}

According to ICH guidelines, precision is the closeness of agreement (degree of scatter) between a series of measurements obtained from multiple sampling of the same homogenous sample under the prescribed condition. ${ }^{13}$ Accuracy of an analytical method describes the closeness of mean test results obtained by the true value (concentration) of the analytics. Both repeatability (intra-day) and reproducibility (inter-day) were measured as follows: solutions containing lowest, intermediate and highest concentrations of the calibration curve i.e. were prepared. Six injections at each of specific concentration levels were injected with in the same day for repeatability and over a period of six days for reproducibility. 


\section{Sensitivity}

The limit of detection (LOD) and lower limit of quantification (LLOQ) were determined by the following equation:

\section{LOD or LLOQ}

Where $\mathrm{K}$ is constant ( 3 for LOD and 10 for LLOQ), $\mathrm{S}_{\mathrm{b}}$ is the standard deviation of the analytical signal, and $\mathrm{S}$ is the slope of the concentration/response graph. As per International Organization for Standardization (ISO) the slope of the calibration defined the instrumental sensitivity response. ${ }^{14}$

\section{Recovery}

Recovery is not improtant validation parameter regarded as essential by the conference report. Most authors say that the value of recovery is not important, as long as the data from LLOQ, LOQ, precision and accuracy are acceptable. ${ }^{14}$ Recovery was determined by measuring the peak area responses from plasma sample spiked with particular standard working solution of analyte before extraction with those from the drug-free plasma samples extracted and the spiked with the same concentration of the analyte after extraction.

\section{Stability}

Chemical stability of an analyte is done in a given matrix under specific condition for a given time interval. Stability of ibuprofen in plasma sample was evaluated with three studies: $8 \mathrm{hr}$ bench top, $24 \mathrm{hr}$ ambient temperature, 1 month frozen $\left(\right.$ at $\left.-20^{\circ} \mathrm{C}\right)$. Six replicates of three QC samples at concentration of $15 \mu \mathrm{g} / \mathrm{ml}$ (LOQ), $45 \mu \mathrm{g} / \mathrm{ml}$ (MCQ), $90 \mu \mathrm{g} / \mathrm{ml}$ (HCQ) was prepared and subsequent HPLC analysis was carried out as describe previously.

\section{Pharmacokinetic analysis}

Above said analytical method was successfully applied in a pharmacokinetics study of Ibuprofen in rabbits. Using the non-compartmental approach, plasma levels of IBP were employed to compute their individual disposition kinetics, viz, $\mathrm{C}_{\max }$ (maximum plasma concentration), $\mathrm{T}_{\max }$ (time to reach maximum plasma concentration), AUC ${ }_{0-\mathrm{t}}$ (area under plasma concentration-time curve, 0 to $12 \mathrm{hr}$ ), $\mathrm{AUC}_{0-\infty}$ (area under plasma concentration time curve, 0 to infinity), $\mathrm{K}_{\mathrm{el}}$ (elimination rate constant) and $\mathrm{t}_{1 / 2}$ (elimination half-life). These pharmacokinetic parameters were calculated using PK Solutions 2.0 TM. Here we use non-compartmental pharmacokinetic data analysis procedure.

The rate of absorption was evaluated by means of the ratio of $\mathrm{C}_{\max } / \mathrm{AUC}_{0-\infty}$. The rate of clearance (CL) and the relative bioavailability $(\mathrm{Fr}$ ) were calculated according to the equation Dose $/ \mathrm{AUC}_{0-\infty}$ and, Mean $\mathrm{AUC}_{0-\mathrm{t}}$ (test)/Mean AUC ${ }_{0-\mathrm{t}}($ reference $) \times 100 \%$. These pharmacokinetic parameters were performed on a personal computer using the program Microsoft Excel ${ }^{\mathbb{}} 2007$ (Microsoft Co., USA).

\section{In-vitro In-vivo correlation (IVIVC)}

A USP PF (United state pharmacopeia (USP), Pharmacopoeial Forum (PF)) Stimuli Article in July 1988 establishes the classification of IVIVC into level A, B and C, which are currently use. Level A correlation is usually estimated by two stage procedure: deconvolution followed by comparison of the fraction of drug absorbed to the fraction of drug dissolved. A correlation of this type is generally linear and represents a point to point relationship between in-vitro dissolution and in-vivo input rate. One alternative is based on a convolution procedure that models the relationship between in-vitro dissolution and plasma concentration in single step.

In the present study a level A correlation was established using de-convolution method. The software Kinetica 5.1 was used performed numerical deconvolution on slow, moderate and fast release formulation.

\section{Statistical Data Analysis}

Statistical data analysis was performed by one way ANOVA between the various groups. A $P$ value of $<0.05$ was considered statistically significant.

\section{RESULTS AND DISCUSSION}

\section{Validation of the propose method Calibration curve}

The calibration curve was constructed by plotting the peak area ratio $(f)$ of ibuprofen to IS versus the nominal concentration $(\mathrm{C})$ of the analyte. The plasma calibration curves were found to be linear over the concentration range of 5 to $100 \mu \mathrm{g} / \mathrm{ml}$ with correlation coefficient 0.999, indicating a strong linear relationship between the variable. The standard curve had a reliable reproducibility over the standard concentrations across the calibration range. The linearity was determined by linear regression analysis. The regression equation of the calibration curve was then used to calculate the concentration of ibuprofen in rabbit plasma. The back calculated values of the concentrations were then statistically evaluated. The back calculated concentrations (mean \pm S.D.) from the representative calibration standards by HPLC determination for ibuprofen and the corresponding regression equations are given in Table 1 . The 


\section{Table 1: Linear Regression Data for the determination of ibuprofen added to rabbit plasma $(n=6)$}

\begin{tabular}{|c|c|}
\hline Spike Concentration in $\mathbf{\mu g} / \mathbf{m l}$ & $\begin{array}{c}\text { Measured concentration } \mathbf{~ i n ~} \mathbf{\mu g} / \mathbf{m l} \\
\text { (Mean } \pm \mathbf{S D} \text { ) }\end{array}$ \\
\hline 5 & $4.952 \pm 0.58$ \\
\hline 10 & $10.91 \pm 1.41$ \\
\hline 20 & $20.68 \pm 2.41$ \\
\hline 40 & $39.22 \pm 2.19$ \\
\hline 60 & $58.09 \pm 4.05$ \\
\hline 80 & $81.21 \pm 2.65$ \\
\hline 10 & $100.732 \pm 4.9$ \\
\hline Equation & $f=0.026 x+0.048$ \\
$R^{2}$ & 0.999 \\
\hline
\end{tabular}

Mean peak area ratios of Ibuprofen to IS presented by $f . \mathrm{R}^{2}$ (Correlation coefficient) is the linearity of the calibration curve used for this treatment.

\begin{tabular}{|c|c|c|c|c|}
\hline $\begin{array}{c}\text { Nomimal } \\
\text { concentration }(\mu \mathrm{g} / \mathrm{ml})\end{array}$ & $\begin{array}{c}\text { Measured } \\
\text { concentration }(\mu \mathrm{g} / \mathrm{ml}) \\
{[\text { Mean] }}\end{array}$ & SD & $\begin{array}{c}\text { Accuracy } \\
(\%)\end{array}$ & $\begin{array}{c}\text { Precision } \\
\text { RSD(\%) }\end{array}$ \\
\hline \multicolumn{5}{|c|}{ Intra-day assay } \\
\hline LLOQ $(5 \mu \mathrm{g} / \mathrm{mL})$ & 5.27 & 0.70 & 105.54 & 13.38 \\
\hline LQC $(15 \mu \mathrm{g} / \mathrm{mL})$ & 15.59 & 2.23 & 103.94 & 14.38 \\
\hline MQC $(45 \mu \mathrm{g} / \mathrm{mL})$ & 44.09 & 2.83 & 97.98 & 6.42 \\
\hline HQC $(90 \mu \mathrm{g} / \mathrm{mL})$ & 94.97 & 6.91 & 105.52 & 7.27 \\
\hline \multicolumn{5}{|c|}{ Inter-day assay } \\
\hline LLOQ $(5 \mu \mathrm{g} / \mathrm{mL})$ & 4.777 & 0.41 & 95.54 & 8.64 \\
\hline LQC $(15 \mu \mathrm{g} / \mathrm{mL})$ & 15.79 & 0.67 & 105.31 & 4.22 \\
\hline MQC $(45 \mu \mathrm{g} / \mathrm{mL})$ & 44.31 & 2.58 & 94.48 & 5.83 \\
\hline HQC $(90 \mu \mathrm{g} / \mathrm{mL})$ & 89.09 & 8.34 & 98.99 & 9.36 \\
\hline
\end{tabular}

Accuracy (\%), [(measured concentration/spike concentration) X 100]; RSD (\%), Relative Standard Deviation [(SD/ mean) $\times 100]$.

\begin{tabular}{|c|c|}
$\begin{array}{c}\text { Table 3: Recovery effect evaluation of lbuprofen in rabbit plasma } \\
(\mathbf{n}=\mathbf{6})\end{array}$ \\
\hline Spike Concentration in $\boldsymbol{\mu g} / \mathrm{ml}$ & Recovery (\%) \\
\hline LLOQ (5) & 88.79066 \\
\hline LQC (15) & 93.14888 \\
\hline MQC (45) & 98.502 \\
\hline HQC (90) & 106.3717 \\
\hline
\end{tabular}

The data represented is the percentage of measured value vs. theoretical value with RSD in parentheses $(n=6) . R^{2}$ is the correlation coefficient of the calibration curve.

\section{Table 4: Short-term and long-term stability data of IBP in rabbit plasma}

\begin{tabular}{|c|c|c|c|c|}
\hline Storage Condition & LQC (15 $\boldsymbol{\mu g} / \mathbf{m l})$ & MQC (45 $\boldsymbol{\mu g} / \mathbf{m l})$ & $\mathbf{H Q C}(\mathbf{9 0} \boldsymbol{\mu g} / \mathbf{m l})$ & $\mathbf{R}^{\mathbf{2}}$ \\
\hline 8 $\mathrm{h}$ bench top & $90.89(11.38)$ & $100.66(4.40)$ & $97.84(6.81)$ & 0.996 \\
\hline 24 h ambient temp. & $101.89(12.88)$ & $96.01 \mathrm{n}(7.32)$ & $103.00(10.15)$ & 0.989 \\
\hline $\begin{array}{c}1 \text { month frozen } \\
\left(-20^{\circ} \mathrm{C}\right)\end{array}$ & $89.6(13.79)$ & $87.08(14.54)$ & $88.35(10.42)$ & 0.995 \\
\hline
\end{tabular}




\begin{tabular}{|c|c|c|c|}
\hline \multicolumn{5}{|c|}{ Table 5: Comparitive pharmacokinetic parameters of IBP } \\
\hline $\begin{array}{c}\text { Pharmacokinetic } \\
\text { Parameters }\end{array}$ & Pure IBP(control) & $\begin{array}{c}\text { Ibujesic } \\
\text { suspension(reference) }\end{array}$ & IBP loaded IPN beads (test) \\
\hline $\mathrm{C}_{\max }(\mu \mathrm{g} / \mathrm{ml})$ & $32.11 \pm 2.03$ & $30.05 \pm 1.93$ & $27.29 \pm 2.25$ \\
\hline $\mathrm{T}_{\max }(\mathrm{h})$ & $1.41 \pm 0.37$ & $1.58 \pm 0.38$ & $2.91 \pm 0.5$ \\
\hline $\mathrm{AUC}_{0-\infty}(\mu \mathrm{g} \cdot \mathrm{h} / \mathrm{ml})$ & $163.34 \pm 10.06$ & $163.21 \pm 10.03$ & $183.70 \pm 18.40$ \\
\hline $\mathrm{AUC}_{0-\mathrm{t}}(\mu \mathrm{g} \cdot \mathrm{h} / \mathrm{ml})$ & $129.98 \pm 5.48$ & $125.62 \pm 5.77$ & $141.70 \pm 18.58$ \\
\hline $\mathrm{t}_{1 / 2}(\mathrm{~h})$ & $4.30 \pm 0.37$ & $4.70 \pm 0.33$ & $0.80 \pm 0.56$ \\
\hline $\mathrm{K}_{\mathrm{el}}(\mathrm{h}-1)$ & $0.16 \pm 0.02$ & $0.15 \pm 0.01$ & $0.34 \pm .03$ \\
\hline $\mathrm{CL}^{-1}(\mathrm{~L} / \mathrm{Kg} \cdot \mathrm{h})$ & $0.36 \pm 0.02$ & $0.37 \pm 0.03$ & $0.15 \pm .02$ \\
\hline $\mathrm{C}_{\max } / \mathrm{AUC} \mathrm{C}_{0-\infty}\left(\mathrm{h}^{-1}\right)$ & $0.20 \pm 0.02$ & $0.19 \pm 0.02$ & 112.79 (compared with reference) \\
\hline $\mathrm{Fr}(\%)$ & N.A & N.A & 109.02 (compared with control) \\
\hline
\end{tabular}

All the values are represented as Mean $\pm S D$ and $n=6$ rabbits were used.

\begin{tabular}{|c|c|c|c|c|c|c|c|c|}
\hline$P$ value & $\mathrm{C}_{\max }$ & $\mathbf{T}_{\max }$ & $A U C_{0-t}$ & $A U C_{0-\infty}$ & $t_{1 / 2}$ & $\mathbf{K}_{\mathrm{el}}$ & $\mathrm{CL}$ & $\mathrm{C}_{\max } / \mathrm{AUC}_{0-\infty}$ \\
\hline & 0.004 & $0.0001<$ & 0.077 & 0.028 & 0.138 & 0.096 & 0.036 & 0.001 \\
\hline
\end{tabular}<smiles>CCOC(=O)C(Cl)(Cl)C(C)(C)C(C)(C)OCC(=O)OCC(=O)Cc1ccccc1Nc1c(Cl)cccc1Cl</smiles><smiles>CC(C)Cc1ccc(C(C)C(=O)O)cc1</smiles>

IBUPROFEN

Figure 1: Structure of Aceclofenac (IS) and Ibuprofen.

linear regression was calculated using Microsoft Excel $^{\circledR}$ program.

\section{Accuracy and precision}

The intra-day and inter-day precision and accuracy for the plasma ibuprofen are summarized in Table 2. Results showed that the intra-day accuracy ranges from $97.98 \%$ to $105.54 \%$ and the intra-day precision was between $6.4 \%$ to $14.28 \%$. The inter-day accuracy ranges from $95.54 \%$ to $105.30 \%$ and the inter-day precision was between $4.22 \%$ to $9.36 \%$.

\section{Specificity}

The retention times for analyte and IS were 8.53 and 3.77 min respectively. No significant interfering peaks from endogenous compounds were observed at the retention times of analyte and IS. The total chromatographic run time was $10 \mathrm{~min}$. No interfering peaks at retention times were found in the chromatogram obtained from the blank plasma, as the area of analytes and internal standard did not differ in the case of successive analysis of matrix from different individual. The results are shown in Figure 2,3,4 and 5.

\section{Sensitivity}

Additional evaluation of the lower limit of quantitation (LLOQ) confirmed that those concentrations fit with the proposed criteria. It is clear that (from Table 1) our method exhibited good sensitivity.

\section{Recovery}

The extraction recovery results are shown in Table 3. Recovery was calculated as the response ratio (analyte peak area/IS peak area) measured in pre-extraction ibuprofen spiked samples $(n=6)$, as a percentage of that measured from post extraction ibuprofen spiked samples $(n=6)$. Results showed that the recovery of analyte ranges from $88.79 \%$ to $106.37 \%$. 


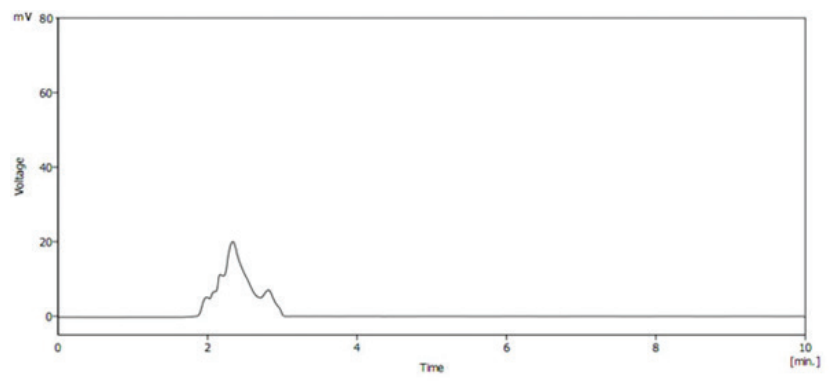

Figure 2: HPLC chromatogram of blank plasma.

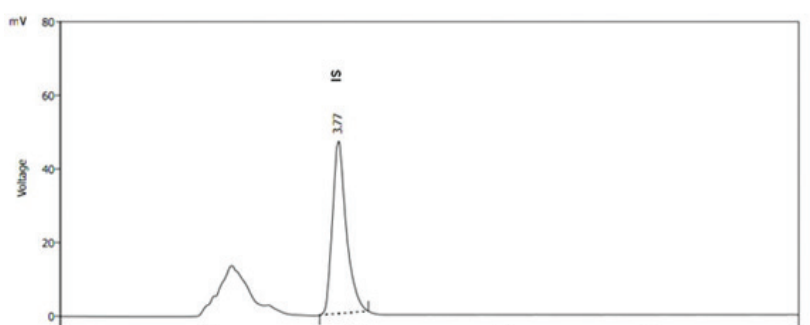

Figure 3: HPLC chromatogram plasma sipked with IS $(25 \mu \mathrm{g} /$ $\mathrm{ml})$.

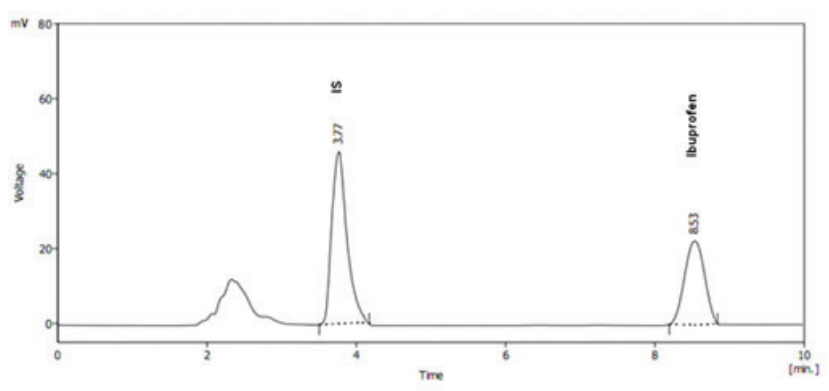

Figure 4: HPLC chromatogram of a calibrator spiked with IBP $(25 \mu \mathrm{g} / \mathrm{ml})$ and IS $(25 \mu \mathrm{g} / \mathrm{ml})$.

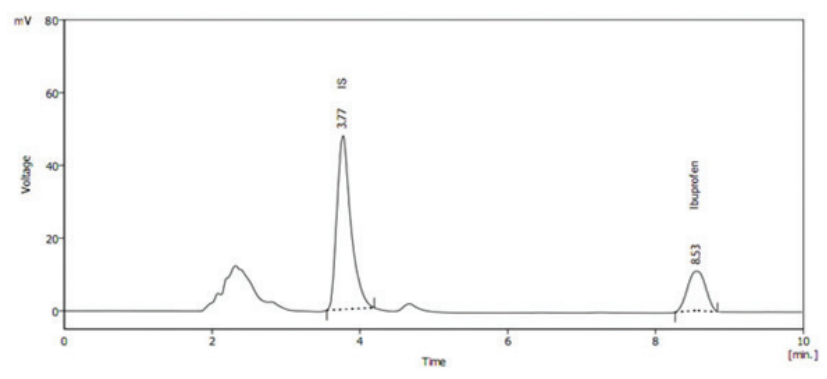

Figure 5: HPLC chromatogram of a plasma sample $1.5 \mathrm{~h}$ after administration of IBP loaded IPN beads.

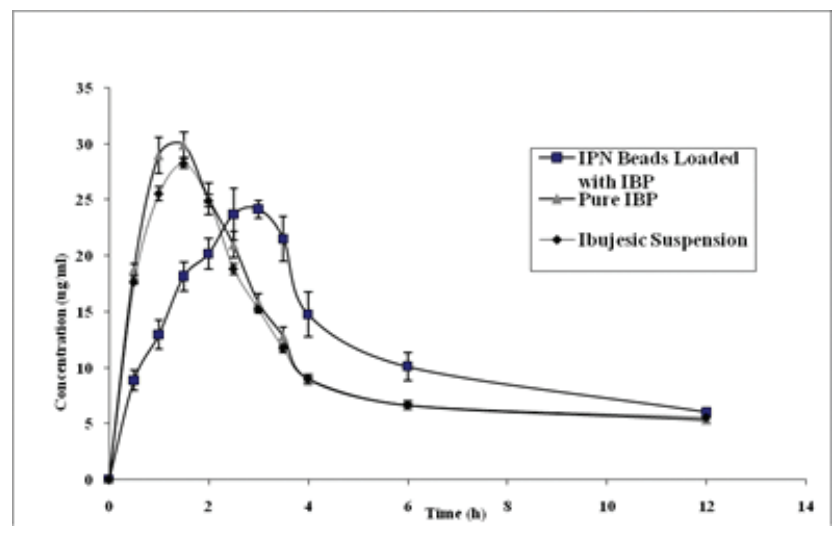

Figure 6: Mean plasma concentration - time curves of IBP after a single oral administration $(n=6)$. All the values are represented as Mean \pm SD.

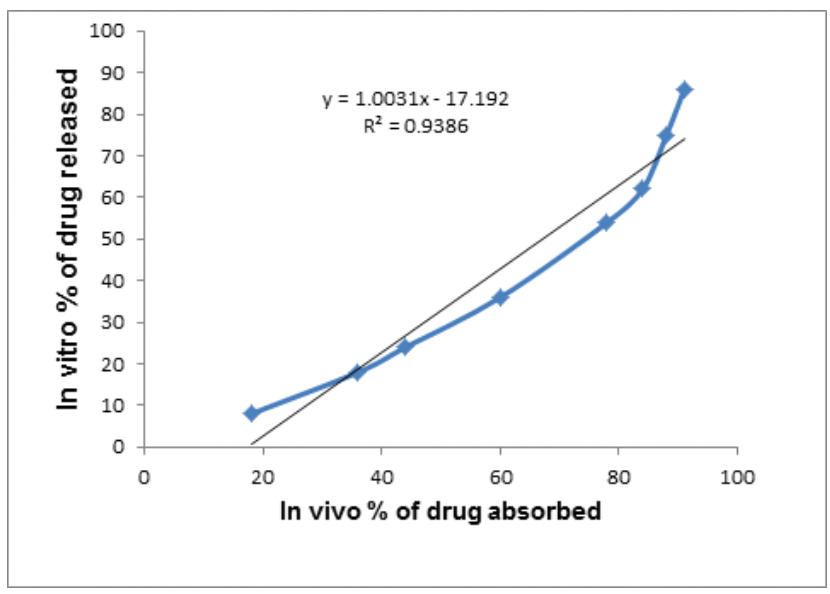

Figure 7: In vitro-in vivo correlation (IVIVC) between in vivo $\%$ of drug absorbed vs. in vitro \% drug released of IPN beads loaded ibuprofen.

\section{Stability}

The stability of ibuprofen in rabbit plasma was determined in various condition which was described earlier. The results of stability of ibuprofen in rabbit plasma are shown in Table 4.

The samples remained within acceptable limits of accuracy and precision. After $8 \mathrm{hrs}$ exposure in bench top the accuracy and precision range from $90.88 \%$ to $100.66 \%$ and $4.40 \%$ to $11.38 \%$ respectively.

In case of $24 \mathrm{hrs}$ at ambient temperature the accuracy and precision vary from $96.01 \%$ to $103 \%$ and $7.32 \%$ to $12.88 \%$. For long term stability $\left(1\right.$ month at $\left.-20^{\circ} \mathrm{C}\right)$ results showed that the accuracy ranges from $87.01 \%$ to $89.6 \%$ and the precision ranges from $10.42 \%$ to $14.54 \%$.

\section{Pharmacokinetic analysis}

In this study, the pharmacokinetic parameters $\mathrm{C}_{\max }, \mathrm{T}_{\max }$, $\mathrm{AUC}_{0-\mathrm{t}}, \mathrm{AUC}_{0-\infty}, \mathrm{K}_{\mathrm{el}}, \mathrm{t}_{1 / 2}, \mathrm{CL}, \mathrm{C}_{\max } / \mathrm{AUC}_{0-\infty}$ and Fr were 
used to compare the test formulation (IPN beads loaded with IBP) against the pure IBP (control) and Ibujesic Suspension (reference). These pharmacokinetic (PK) parameters derived from the plasma IBP data are summarized in Table 5. The plasma concentration (mean \pm SD) of ibuprofen attained at different time intervals, following oral administration of control, reference and the test formulation are depicted in Figure 6. Table 6 shows the $P$ values of different pharmacokinetic parameters.

The main aim of this study was to compare the bioavailability of the test formulation with control and the reference product. The prominent parameters used to measure bioavailability were $\mathrm{AUC}_{0-\mathrm{t}}$ and $\mathrm{AUC}_{0-\infty}$ and absorption rate were indicated by $\mathrm{C}_{\max }, \mathrm{T}_{\max }$ and $\mathrm{C}_{\max } /$ $\mathrm{AUC}_{0-\infty}$. While the $\mathrm{C}_{\max }$ (mean $\pm \mathrm{SD}$ ) value for the Control $(32.11 \pm 2.03 \mu \mathrm{g} / \mathrm{ml})$ and reference $(30.05 \pm$ $1.93 \mu \mathrm{g} / \mathrm{ml}$ ) reached quickly and then fell rapidly, the $\mathrm{C}_{\max }$ of test formulation $(27.29 \pm 2.25 \mu \mathrm{g} / \mathrm{ml})$ rises slowly as well as falls slowly $(P<0.05)$. The $\mathrm{T}_{\max }$ (mean $\pm \mathrm{SD})$ value for the control $(1.41 \pm 0.37 \mathrm{~h})$ and reference $(1.58 \pm 0.38 \mathrm{~h})$ were lower in comparison with the test formulation $(2.91 \pm 0.5 \mathrm{~h})$ which revealed that the formulation has lower rate of absorption than the control and reference $(P<0.0001)$. This can also be attributed from the $\mathrm{C}_{\max } / \mathrm{AUC}_{0-\infty}$ pharmacokinetic parameter which confirmed that the test formulation $\left(0.15 \pm 0.02 \mathrm{~h}^{-1}\right)$ has lower absorption rate with respect to the control $\left(0.20 \pm 0.02 \mathrm{~h}^{-1}\right)$ and reference $\left(0.19 \pm 0.02 \mathrm{~h}^{-1}\right)$. The difference between the groups were found to be statistically significant at $P<0.05$.

The extent of absorption (bioavailability) e.g $\mathrm{AUC}_{0-\mathrm{t}}$ and $\mathrm{AUC}_{0-\infty}$ were found to be higher in the test formulation $(141.70 \pm 18.58 \mu \mathrm{g} \cdot \mathrm{h} / \mathrm{ml}$ and $183.70 \pm 18.40 \mu \mathrm{g} . \mathrm{h} / \mathrm{ml})$ with respect to the control $(129.98 \pm 5.48 \mu \mathrm{g} \cdot \mathrm{h} / \mathrm{ml}$ and $163.34 \pm 10.06 \mu \mathrm{g} . \mathrm{h} / \mathrm{ml}$ ) and the reference (125.62 \pm $5.77 \mu \mathrm{g} . \mathrm{h} / \mathrm{ml}$ and $163.21 \pm 10.03 \mu \mathrm{g} . \mathrm{h} / \mathrm{ml})$. While the statistical difference between the groups was found to be insignificant in case of $\mathrm{AUC}_{0-\mathrm{t}}(P>0.05)$, significant difference in $\mathrm{AUC}_{0-\infty}(P<0.05)$ was noted. Moreover significantly higher $\mathrm{t}_{1 / 2}(4.80 \pm 0.56 \mathrm{~h})$ value was noted with the test formulation than the control and the reference. The rate of clearance (CL) was also slower in the test formulation $(0.34 \pm 0.03 \mathrm{~L} / \mathrm{Kg} . \mathrm{h})$ in comparison with others. Although the $\mathrm{K}_{\mathrm{el}}$ of the test formulation ( $0.15 \pm$ $\left.0.02 \mathrm{~h}^{-1}\right)$ was almost similar to that of the reference $\left(0.15 \pm 0.01 \mathrm{~h}^{-1}\right)$, the parameter differed with respect to control $\left(0.16 \pm 0.02 \mathrm{~h}^{-1}\right)$. The relative bioavailability obtained with the test formulation was $109.02 \%$ and $112.79 \%$ when compared with the control and reference respectively.
It can be concluded from the studies of the above experimental Pharmacokinetic parameters that ibuprofen loaded IPN beads developed through dispersion of SCMX: SAL: IBP in the ratio 1.5:1.5:1.5 in 2\% aluminum chloride solution which acts as cross linking agent, can provide sustained release of the drug.

\section{In vitro in vivo correlation (IVIVC)}

To assess the viability and validity of the sustaining nature of IPN beads, IVIVC study is essential, since prolonged release products may be especially suited for this kind of study. Level A correlation is considered to be most informative of all levels of correlation. When the drug released from our best optimized formulation was plotted against the drug absorbed, a linear correlation was obtained (Figure 7). A higher value of correlation coefficient suggested that a good correlation exist between in vitro and in vivo data.

\section{CONCLUSION}

The bioanalytical method was simple and rapid for the determination of IBP in rabbit plasma. A one-step protein precipitation provided a simple, rapid and economic procedure. Other methods described in the literature use sophisticated techniques for the quantification of IBP in biological matrices, like LC-MS and fluorescence spectroscopy. ${ }^{15,16}$ Despite the high sensitivity of these techniques, there is high cost as well as a lot of time spent with clean up and extraction of drug. This HPLC analysis method showed excellent precision, accuracy, stability, specificity and recovery. Therefore, this method was suitable and applied to monitor the concentration of IBP in rabbit plasma.

It is concluded from our research work that in vivo IPN beads loaded with IBP possesses sustained the anti inflammatory action for a prolong time with less side effect. The present experiment revealed that the pharmacokinetic profiles, mainly bio-availability of IPN beads loaded with IBP is much better than the marketed formulation of Ibugesic suspension. Based on our research finding, the modern formulation of IBP can be introduced in the market for better patient compliance.

\section{ACKNOWLEDGEMENT}

The authors wish to thank University grant commission (UGC), New Delhi for the financial assistance rendered for completing this valuable study. Authors also wish to thanks Jadavpur University, Kolkata, M/S Albert David Limited and M/S Deys Medical Stores (Mfg) for gifting 
IBP (Indian Pharmacopoeia) and xanthan gum for the present research work.

\section{CONFLICT OF INTEREST}

The authors have no conflict of interest to declare.

\section{ABBREVIATION USED}

IBP: Ibuprofen; ANOVA: Analysis of Variance; EDTA: Ethylene Diamine Tetra Acetic acid; HPLC: High performance liquid chromatography; ICH: International Conference on Harmonisation; LOD: Limit of Detection; LLOQ: Lowe Limit of Quantification; AUC: Area under curve; SD: Standard deviation.

\section{REFERENCES}

1. Mallick S, Pradhan SK, Mohapatra R. Effects of microcrystalline cellulose based comilled powder on the compression and dissolution of ibuprofen. Int J Biol Macromol. 2013;60:148-55. http://dx.doi.org/10.1016/j. ijbiomac.2013.05.021; PMid:23732329.

2. Busson M, Update on ibuprofen: review article. J Int Med Res. 1986;14:5362. PMid:3516751.

3. Maity S, Sa B. Ca-carboxymethyl xanthan gum mini-matrices: Swelling, erosion and their impact on drug release mechanism. Int J Biol Macromol. 2014;68:78-85. http://dx.doi.org/10.1016/j.ijbiomac.2014.04.036; PMid:24768968.

4. Palapparambil SG, Ray D, Sahoo PK. Characteristics of xanthan gumbased biodegradable superporous hydrogel. Int J Biol Macromol. 2009;45(4):364-71. http://dx.doi.org/10.1016/j.ijbiomac.2009.07.007; PMid:19643130.

5. Sellimi S, Younes I, Ayed HB, Maalej H, Montero V, Rinaudo M, et al. Structural, physicochemical and antioxidant properties of sodium alginate isolated from a Tunisian brown seaweed. Int J Biol Macromol. 2015;72:135867. http://dx.doi.org/10.1016/j.jibiomac.2014.10.016; PMid:25453289.
6. Ray R, Maity S, Mandal S, Chatterjee TK, Sa B. Studies on the release of ibuprofen from $\mathrm{Al}^{+}$ion cross-linked homopolymeric and interpenetrating network hydrogel beads of carboxymethyl xanthan and sodium alginate. Adv Polym Tech. 2011;30(1):1-11. http://dx.doi.org/10.1002/adv.20199.

7. Ray R, Pal R, Karan S, Sa B, Chatterjee TK. Evaluation of pharmacological activities of Ibuprofen loaded Interpenetrating polymer network (IPN) beads from sodium carboxymethyl xanthan and sodium alginate on rats. Pharmacology online. 2010;2:719-36.

8. Ray R, Maity S, Mandal S, Chatterjee TK, Sa B. Development and evaluation of a new interpenetrating network bead of sodium carboxymethyl xanthan and sodium alginate for ibuprofen release. Pharmacol Pharm. 2010;1(01): 9-17. http://dx.doi.org/10.4236/pp.2010.11002.

9. Guidance for Industry: Estimating the Maximum Safe Starting Dose in Initial Clinical Trials for Therapeutics in Adult Healthy Volunteers. U.S. Department of Health and Human Services Food and Drug Administration Center for Drug Evaluation and Research (CDER). Pharmacol Toxicol. 2005.

10. Bramlage $P$, Goldis A. Bioequivalence study of three ibuprofen formulations after single dose administration in healthy volunteers. BMC Pharmacol. 2008;8(1):18. http://dx.doi.org/10.1186/1471-2210-8-18; PMid:18959779 PMCid:PMC2613135.

11. Ghosh S, Barik BB. A Comparative Study of the Pharmacokinetics of Conventional and Sustained-release Tablet Formulations of Aceclofenac in Healthy Male Subjects. Trop J Pharm Res. 2010;9(4):395-99. http://dx.doi. org/10.4314/tjpr.v9i4.58939.

12. Shah VP, Midha KK, Findlay JW, Hill HM, Hulse JD, McGilveray IJ et al. Bioanalytical method validation-a revisit with a decade of progress. Pharm Res. 2000;17(12):1551-7. doi: 10.1023/A:1007669411738. http://dx.doi. org/10.1023/A:1007669411738.

13. International Conference on Harmonization $(\mathrm{ICH})$. Validation of Analytical Methods: Definitions and Terminology. ICH Q2 A. 1994.

14. Causon R. Validation of chromatographic methods in biomedical analysis viewpoint and discussion. J Chromatogr B. 1997;689(1):175-80. http://dx.doi. org/10.1016/S03784347(96)00297-6

15. Reddy RS, Chandiran IS, Jayaveera K.N, Divi KR. Quantification of Ibuprofen in human plasma by using High Throughput Liquid Chromatography-tandem mass spectrometric method and its applications in pharmacokinetics. Arch Appl Sci Res. 2010;2(3):101-11.

16. Matkovic SR, Valle GM, Briand LE. Quantitative analysis of ibuprofen in pharmaceutical formulations through FTIR spectroscopy. Lat Am appl res 2005;35(3):189-95.

\section{SUMMARY}

- Ibuprofen beads, sodium carboxymethyl xanthan and sodium alginate was prepared by inotropic gelation process using $\mathrm{AlCl}_{3}$ as a cross linking agent.

- The pharmacokinetic parameters of ibuprofen (IBP) in rabbits were determined to compare the bioavailability of the drug from IPN beads with that from pure IBP and IBP Suspension. Based on research finding the relative bioavailability of Ibuprofen from the IPN beads was higher from the both control and reference products.

- The present research work revealed that IPN beads could be a suitable dosage form for IBP to achieve a sustained drug release 